\title{
Sexual harassment of a king penguin by an Antarctic fur seal
}

\author{
P. J. Nico de Bruyn ${ }^{1}$, Cheryl A. Tosh ${ }^{1}$ and Marthán N. Bester ${ }^{1}$
}

(1) Mammal Research Institute, Department of Zoology and Entomology, University of Pretoria, Pretoria, 0002, South Africa

\author{
P. J. Nico de Bruyn \\ Email: pjndebruyn@zoology.up.ac.za
}

\section{Abstract}

Males of gregarious pinnipeds are often aggressive to conspecifics and sexual coercion of females is commonplace. Males of some pinniped species have been known to attempt interspecific copulation, occasionally being successful in producing hybrid offspring. The most extreme case of interspecific sexual coercion reported concerned species from different families. We report a case of interspecific sexual harassment bridging the rank of vertebrate class.

Sexual coercion and male aggression directed towards females are well studied, yet not clearly understood activities in nature, boasting numerous contested hypotheses (CluttonBrock and Parker 1995). For many pinniped species, and particularly in gregarious breeders, sexual behaviour is aggressive and energetically costly for males and potentially lethal for females (Le Boeuf 1972; Miller 1975; McCann 1980; Le Boeuf and Mesnick 1990; Chilvers et al. 2005). In a large number of pinniped species, sexual dimorphism in favour of males is significant (e.g. southern elephant seals Mirounga leonina; Laws 1993) which can allow sexual coercion in some form (e.g. Clutton-Brock and Parker 1995). Occasionally, the sexual intentions of males may extend beyond the restrictions of conspecifics. Interspecies sexual behaviour in pinnipeds is widely documented and ranges from successful hybridisation between closely related species (e.g. Kerley 1983; Wynen et al. 2000) or even between different genera (e.g. Kovacs et al. 1997), to non-reproductive male sexual advances (e.g. Wilson 1975; Best et al. 1981; Mortenson and Follis 1997; Hayward 2003). Such behaviour seems to be highly individualistic. To our knowledge, however, no pinniped species have ever been documented to bridge the level of vertebrate class in their copulatory attempts.

A young adult male Antarctic fur seal (Arctocephalus gazella) in good condition was observed attempting to copulate with an adult king penguin (Aptenodytes patagonicus) of unknown sex, at Trypot beach on sub-Antarctic Marion Island (46 $52^{\circ}$ 'S, 37²51'E) during the mid-morning of 21 December 2006 (Fig. 1a, b). The approximate weight of this fur 
seal, based on estimated age, was between 100 and $120 \mathrm{~kg}$ (Bonner 1968), while that of an adult king penguin varies between 10-21 kg (Hänel and Chown 1998). The fur seal was first seen as it subdued the penguin by resting its body on the latter (Fig. 1a). The penguin struggled by rapidly moving its flippers and attempting to stand up, but the attempts appeared feeble suggesting that the seal had subdued the penguin some time prior to the commencement of our observation. The penguin showed no outward signs of injury. The seal alternated between resting on the penguin (Fig. 1a) and bouts of pelvic thrusting copulatory behaviour (King 1983), attempting to penetrate the cloaca of the penguin (Fig. 1b). Although the visible penis of the seal provided evidence for its intention (Fig. 1b), it did not appear to be successful in insertion. This sequence of events continued for 45 min, with resting periods between copulatory attempts, lasting approximately 3 and $8 \mathrm{~min}$, respectively. After $45 \mathrm{~min}$, the seal abruptly moved into the sea and completely ignored the penguin until observations ceased approximately $1 \mathrm{~h}$ later. The penguin remained where the seal had left it until observations ceased and made no attempt to stand or move away, although the head was held erect. Brief inspection of the cloaca of the penguin supported our observations that insertion did not take place, since the cloaca appeared normal, undamaged and presented no evidence of the presence of ejaculate. The penguin's breathing was laboured but otherwise the animal appeared in good condition. Bonner (1968) describes the typical duration of intraspecific successful copulation in this seal species as between $2 \frac{1}{2}$ and 6 min, at the end of which the bull dismounts and the cow remains where she is. Copulatory attempts with conspecifics that continue for longer than 20 min appear to be as a result of unsuccessful intromission by the male, even while the female is passive but does not make her vulva accessible (Bonner 1968). Bulls typically support their own weight on their foreflippers when straddling the prone female seal, and instances where the bull rests on the female are rare (Bonner 1968). Hence, aside from the interclass aspect, the observed fur seal's sexual behaviour does not conform to normal copulatory behaviour, in that the interaction continued for much longer than is usual for this species, and the coercion of the penguin by the seal was evident as the latter rested on the penguin to prevent its escape. 

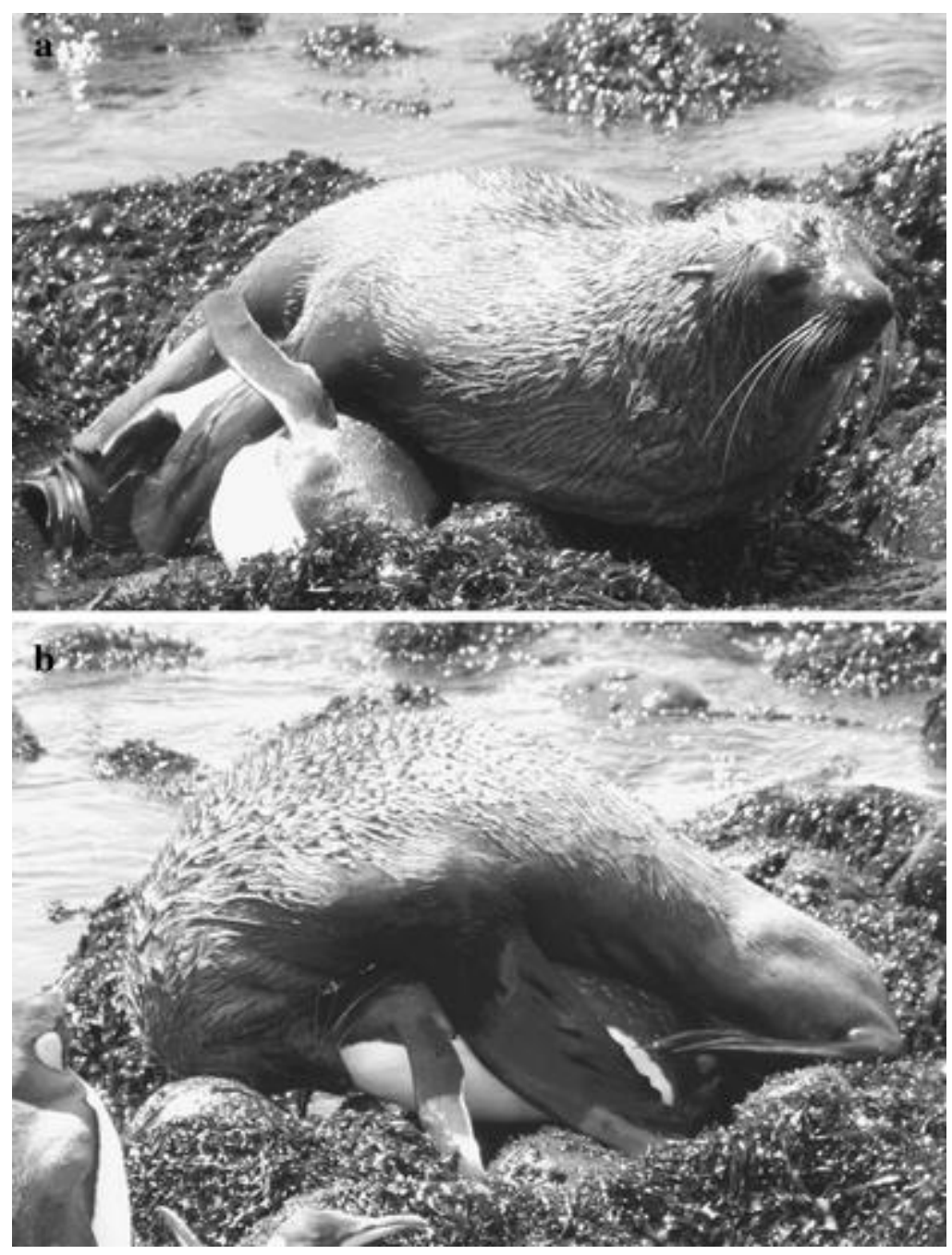

Fig. 1 a Young male Antarctic fur seal (Arctocephalus gazella) resting on an adult king penguin (Aptenodytes patagonicus) during the process of sexual harassment. b Young male Antarctic fur seal (Arctocephalus gazella) attempting to copulate with an adult king penguin (Aptenodytes patagonicus) on Marion Island. Photo: P.J.N. de Bruyn

Male Antarctic fur seals reach sexual maturity at 3-4 years of age, but are generally unable to defend territories until the age of about 8 years (Payne 1979). The onset of sexual maturity results in heightened aggression and sexual arousal as is usual for the species, but social immaturity (i.e. the presence of larger older bulls) precludes access to receptive females during the breeding season (McCann 1980). The natural but inevitable "cul-de-sac" sexual excitement of these younger males towards conspecifics is thought to lead, in rare cases, to the abnormal interspecific sexual behaviour seen in this study and in other species (Wilson 1975; Best et al. 1981; Mortenson and Follis 1997; Hayward 2003). The great majority of male seals responsible for this behaviour are documented as being either subadults or young adults and consequently can be said to be sexually inexperienced. Rose et al. (1991) interpreted such "stimulus generalisation" by sexually inexperienced animals as a likely product of selection for high sexual motivation. 
However, the behaviour reported in this study was seen towards the end of the Antarctic fur seal breeding season (late November-December; Kerley 1983) after the disintegration of the breeding territories/harems and cessation of typical breeding season aggression and associated sexual stimuli. What then caused this unusual behaviour?

At Marion Island, Antarctic fur seal males are implicated in another form of unique behaviour: the shore-based predation of king penguins during the period August-October (Hofmeyr and Bester 1993). While this behaviour has been documented predominantly on the south coast of the island (Hofmeyr and Bester 1993), we observed the killing of two king penguins at Trypot beach (northeast coast) on 20 October 2006 by a young adult male Antarctic fur seal. We considered whether the seal observed in this study was perhaps a penguin killer and that the excitement induced by initial predatory behaviour could have been redirected into sexual arousal on this occasion. Evolutionary biologists and behaviourists argue for the closely associated development of aggressive/hunting and sexual behaviour in numerous species; indeed most courtship displays in birds, for example, are thought to be co-opted from aggressive displays (e.g. Borgia and Coleman 2000). The hormonal (particularly testosterone; e.g. Bester 1990) surge in this Antarctic fur seal due to the recent completion of the breeding season, the known shore-based predation on king penguins at this beach, and the evolutionary proximity of the killing and mating instincts may have combined to result in the observed behaviour. Alternatively, the incident may simply have arisen from a sexual manifestation of the play instinct of the seal. Seals in general and particularly juveniles are known to be playful and some participate in mock, or play, mating behaviour (e.g. common seal Phoca vitulina; Thompson 1988). Thus, the observed behaviour of this young male Antarctic fur seal may have constituted such 'preparation' for later involvement in actual breeding with conspecifics. The identification of cause for this scenario is difficult, but whatever it may be, this observation of highly unusual animal behaviour demonstrates the challenges to our understanding of the subject.

\section{References}

Best PB, Meyer MA, Weeks RW (1981) Interactions between a male elephant seal Mirounga leonina and Cape fur seals Arctocephalus pusillus. S Afr J Zool 16:59-66

Bester MN (1990) Reproduction in the male Subantarctic fur seal Arctocephalus tropicalis. J Zool 222:177-185

Bonner WN (1968) The fur seal of South Georgia. British Antarctic Survey Scientific Reports No. 56, London

Borgia G, Coleman SW (2000) Co-option of male courtship signals from aggressive display in Bowerbirds. Proc R Soc Lond B 267:1735-1740 
Chilvers BL, Roberton BC, Wilkinson IS, Duignan PJ, Gemmell NJ (2005) Male harassment of female New Zealand sea lions, Phocarctos hookeri: mortality, injury, and harassment avoidance. Can J Zool 83:642-648

Clutton-Brock TH, Parker GA (1995) Sexual coercion in animal societies. Anim Behav 49:1345-1365

Hänel C, Chown S (1998) An introductory guide to the Marion and Prince Edward Island special nature reserves 50 years after annexation. Department of Environmental Affairs and Tourism, South Africa

Hayward JL (2003) Sexual aggression by a male northern elephant seal on harbour seal pups in Washington. Northwest Nat 84:148-150

Hofmeyr GJG, Bester MN (1993) Predation on king penguins by Antarctic fur seals. S Afr J Antarct Res 23:71-74

Kerley GIH (1983) Comparison of seasonal haul-out patterns of fur seals Arctocephalus tropicalis and A. gazella on subantarctic Marion Island. S Afr J Wildl Res 13:71-77

King JE (1983) Seals of the world. Oxford University Press, Oxford

Kovacs KM, Lydersen C, Hammill MO, White BN, Wilson PJ, Malik S (1997) A harp seal $\times$ hooded seal hybrid. Mar Mamm Sci 13:460-468

Laws RM (1993) Identification of species. In: Laws RM (ed) Antarctic seals: research methods and techniques. Cambridge University Press, Cambridge, pp 1-6

Le Boeuf BJ (1972) Sexual behavior in the northern elephant seals Mirounga angustirostris. Behaviour 41:1-26

Le Boeuf BJ, Mesnick S (1990) Sexual behavior of northern elephant seals: I. Lethal injuries to adult females. Behaviour 116:143-162

McCann TS (1980) Territoriality and breeding behaviour of adult male Antarctic fur seal, Arctocephalus gazella. J Zool 192:295-310

Miller EH (1975) Social and evolutionary implications of territoriality in adult male New Zealand fur seals, Arctocephalus forsteri (Lesson, 1828), during the breeding season. Rapp P-v Réun Cons Int Explor Mer 169:170-187 
Mortenson J, Follis M (1997) Northern elephant seal (Mirounga angustirostris)

aggression on harbour seal (Phoca vitulina) pups. Mar Mamm Sci 13:526-530

Payne MR (1979) Growth in the Antarctic fur seal Arctocephalus gazella. J Zool 187:120

Rose NA, Deutsch CJ, Le Boeuf BJ (1991) Sexual behavior of male northern elephant seals: III. The mounting of weaned pups. Behaviour 119:171-192

Thompson PM (1988) Timing of mating in the common seal (Phoca vitulina). Mamm Rev 18:105-112

Wilson SC (1975) Attempted mating between a male grey seal and female harbour seals. J Mamm 56:531-534

Wynen LP, Goldsworthy SD, Guinet C, Bester MN, Boyd IL, Gjertz I, Hofmeyr GJG, White RWG, Slade R (2000) Postsealing genetic variation and population structure of two species of fur seal (Arctocephalus gazella and A.tropicalis). Mol Ecol 9:299-314 